\title{
SPOROZOITE MALARIA VACCINE WHERE DO WE STAND?
}

\author{
V. NUSSENZWEIG*, S. NUSSENZWEIG**
}

\begin{abstract}
SUMMARY
A. sporozoite malaria vaccine which elicits high levels of antibodies to the circumsporozoite (CS) protein may protect part of the human population in areas of low endemicity. Other possible targets of a sporozoite vaccine are the liver stages, but in this case the effector cells are T-lymphocytes which recognize sporozoite-

derived peptides in association with products of the major histocompatibility complex. There is no evidence that the variation observed in the CS protein of $P$. falciparum is driven by immunological pressure, nor that this variation will be a major impediment to vaccine development.
\end{abstract}

\section{RÉSUMÉ: Paludisme: un vaccin antisporozoïte. Où en sommes-nous?}

Un vaccin contre le paludisme de spécificité antisporozoïte, qui élicite une réponse anticorpale élevée vis-à-vis de la protéine circumsporozoïtaire (CS), pourrait protéger une partie de la population située dans des zones de faible endémie. D'autres vaccins antisporozoïtaires peuvent être envisagés contre les stages hépatiques du parasite. Cependant, dans ce cas, les cellules effectrices sont les cellules lymphocytaires $\mathrm{T}$ qui reconnaissent des peptides dérivés des sporozoïtes en association avec les produits du complexe majeur d'histocompatibilité. Il n'y a aucune évidence que la variation antigénique de la CS protéine de $P$. falciparum soit due à une pression immunologique, ou que cette variation soit un obstacle majeur au développement d'un vaccin contre le paludisme.
In 1987 a few dozen student volunteers from the School of Medicine and Dentistry at the University of Maryland were vaccinated with a synthetic peptide vaccine (NANP) $)_{3}$-tetanus toxoid in which the peptide was a 12 amino acid sequence from a sporozoite membrane protein, the circumsporozoite (CS) protein. This was the first peptide vaccine against an infectious agent tried in man. It had been tested extensively in mice and rabbits at New York University and at Hoffmann-La Roche, and it elicited high titers of antibody. However, the antibody titers to the peptide in the human volunteers were disappointingly low (Herrington et al., 1987).

At the same time investigators from the US Army and Navy were trying in humans a recombinant vaccine consisting almost entirely of a series of NANP repeats (Ballou et al., 1987). The antibody titers in the Army-Navy volunteers were as low or even lower. A few months later some volunteers were challenged with infected mosquitoes. We were pessimistic about the outcome because in the rodent

\footnotetext{
* Department of Pathology, Division of Immunology.

** Department of Medical and Molecular Parasitology, New York University Medical Center, 550 First Avenue, New York, NY 10016, USA.
}

malaria model, $P$. berghei, high titers of antibody were necessary to neutralize injected sporozoites (Zavala et al., 1987). The volunteers were challenged with five heavily infected mosquitoes (Davis et al., 1989). A few army volunteers were also challenged and the result of both trials is summarized in Table $I$.

Not only were two volunteers (those with the highest antibody titers) protected, but in some of the others there was a delay in the prepatent period indicating that a large proportion of the injected sporozoites had been neutralized. These results indicate that partial protection against $P$. falciparum infection can be achieved with vaccines which elicit high levels of antibodies to NANP repeats, provided that the challenge dose is small.

The key finding which led to the development of the synthetic and recombinant vaccines was the observation that mice, monkeys and humans could be protected against sporozoite challenge by vaccination with irradiated sporozoites (Clyde et al., 1973; reviewed in Nussenzweig and Nussenzweig, 1989). The human volunteers were vaccinated by the bite of hundreds of infected, irradiated mosquitoes. A total of 11 volunteers were vaccinated with $P$. falciparum and five were protected against challenge. In some instances the challenge was performed with dozens of mosquitoes infected either with the homologous strains of sporozoites, 
TABLE I. - Summary of results of human trials of two $P$. falciparum vaccines containing products of the circumsporozite protein.

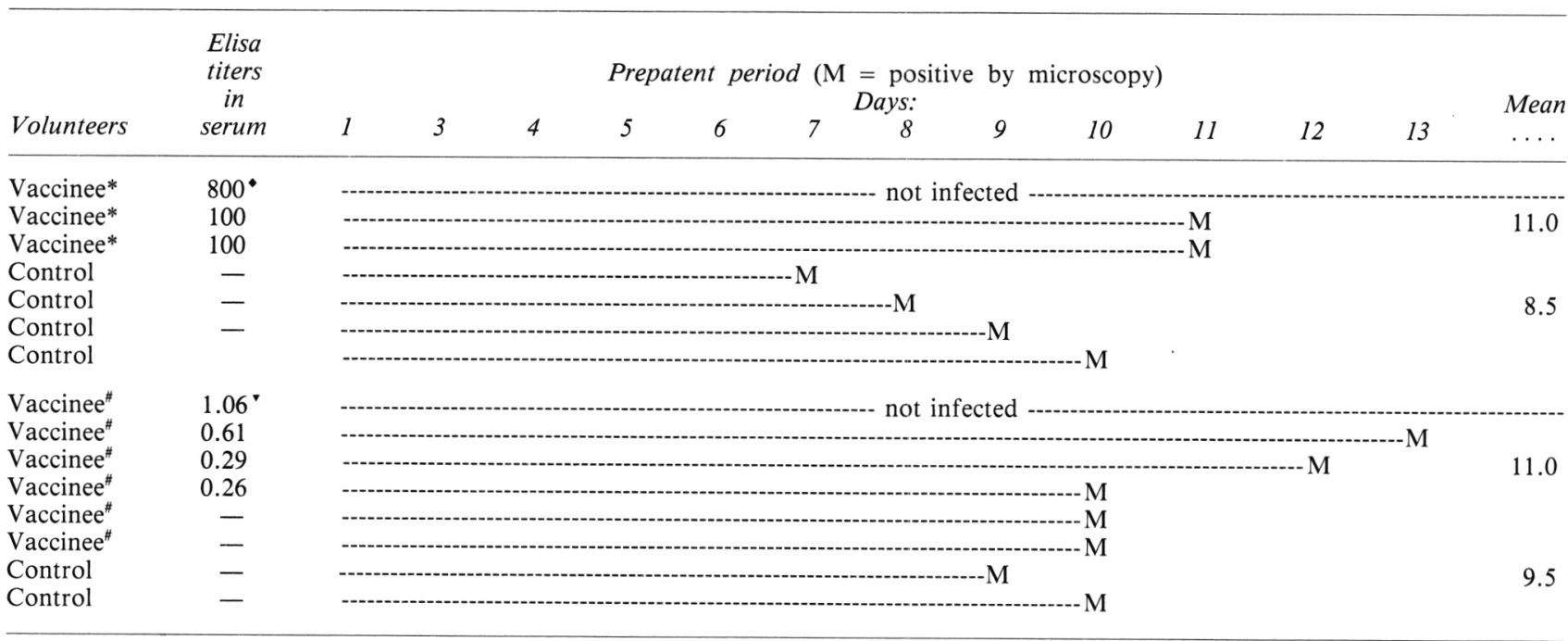

*These volunteers were vaccinated with (NANP) ${ }_{3}$-tetanus toxoid and challenged with five mosquitoes (Herrington et al., 1987). The mean sporozoite content in the mosquitoes was 220,994 , which is much larger than that found in most Anopheles from endemic areas (Davis et al., 1989).

"These volunteers were vaccinated with a recombinant CS product and challenged with five mosquitoes (Ballou et al., 1987).

- Reciprocal IgG anti-(NANP) 3 titer (pre-challenge).

-Absorbance at a serum dilution of $1 / 50$.

or with strains originating from widely diverse geographical regions of the world. Also, two out of five volunteers were protected against $P$. vivax when immunized by the bite of $P$. vivax-infected mosquitoes; again, the challenging and immunizing strains were sometimes different. Therefore, the existing evidence does not support the speculation that observed polymorphisms of the CS protein will hinder vaccine development.

Other important findings were that antibodies in the serum of the protected animals reacted with the surface of sporozoites and neutralized their infectivity. This was followed by the identification of the CS protein by monoclonal antibodies and the demonstration that these antibodies were also protective when passively administered to naive mice.

The cloning of the CS gene, first in P. knowlesi and then in many other species of malaria parasites, permitted the clarification of the structure of the CS protein. The CS gene codes for 300-400 amino acids which can be subdivided into distinct domains. The central area consists of tandem repeats and is rich in amino acids commonly found in reverse turns. In every experimental model tried, monoclonal antibodies to the repeats neutralized sporozoite infectivity. The amino acid sequence of the subunit repeats is species-specific, and can vary even within the same species or subspecies. However, no variation has been detected in the repeat sequence of $P$. falciparum, the most dealy malaria parasite.
Other important features of the CS protein are the presence of conserved pairs of cysteines and of regions which contain a considerable number of charged residues, on each side of the repeat domain. The sequence of amino acids surrounding the first pair of cysteines has homology to thrombospondin.

These findings point to the urgent need to develop immunogens which elicit high titers of antibodies to the $P$. falciparum NANP repeat in humans. In the trials with the NANP-tetanus toxoid vaccine, the frequency and magnitude of the antibody response of the volunteers increased with the dose of conjugate. Unfortunately the dose of the conjugate cannot be increased due to the toxicity of tetanus toxoid. Also this vaccine does not contain T-cell epitopes of the CS protein and therefore the immune response would not be boosted in the endemic areas by the bite of infected mosquitoes.

Our approach to these problems has been to develop entirely synthetic, and chemically defined multiple antigen peptides (MAPs) containing $\mathrm{B}$ and $\mathrm{T}$ epitopes from the CS protein. MAPs consist of an oligomeric branching lysine core and dendritic arms containing $\mathrm{B}$ and $\mathrm{T}$ epitopes. Additional advantages of the MAPs is that they can be engineered to contain several T-epitopes, and that the portions of an antigenic molecule which are «neutral », or even have a suppressive effect on the immune response, can be avoided. In the $P$. berghei model, MAPs vaccines elicited 
very high titers of antibodies to sporozoites, and protected against challenge (Tam et al., 1990).

We are now developing MAPs containing NANP repeats and T-helper epitopes from $P$. falciparum. One complication is that T-epitopes may be MHC-restricted, although there are now several examples of universal $\mathrm{T}$-epitopes, including one described in the C-terminal end of the CS protein (Sinigaglia et al., 1988). Also, most individuals from an endemic area responded to at least one out of six peptides from variant regions of three different $P$. falciparum CS proteins (DeGroot et al., 1988).

Dr. Nardin and collaborators are searching for additional T-epitopes in a group of human volunteers who are being submitted again to the bite of infected irradiated mosquitoes at the University of Maryland. Forty T-cell clones were obtained, and five chosen randomly for further analysis. All recognized the same amino acid sequence, the NANPNVDPNANP from the repeat domain (Nardin et al., 1989). This is a non variant epitope, found in all strains of malaria parasites. The frequency with which this conserved epitope is recognized by immune individuals is not known. This information is essential before it is decided that the NANPNVDPNANP should be included in a MAPs.

Recent evidence in rodent systems indicates that immunization with sporozoite antigens can elicit protective immunity to the liver stages. In this case the parasite is intracellular and the effector arm of the immune response consists of T-cells which directly destroy the infected hepatocytes and/or release lymphokines which inhibit the development of the liver stages (EEF). In either case, the T-cells must recognize processed parasite antigens in association with products of the major histocompatibility complex (MHC).

The key observation which led to these new developments was that $\gamma$-interferon, a product of $\mathrm{T}$-cells, inhibited very effectively the development of EEF (Ferreira et al., 1986). Soon afterwards two groups independently showed that the inactivation of $\mathrm{CD}^{+}$cells in $P$. bergheiand $P$. yoelii- vaccinated mice reversed their protective immunity (Schofield, et al., 1987; Weiss et al., 1988). A similar effect was observed in some experiments when the vaccinated mice were treated with antibodies to $\gamma$-interferon. That is, it appears now that in these rodent models both antibodies and $\mathrm{CD}^{+} \mathrm{T}$-cells play a role in protective immunity to sporozoites. There is, however, no evidence yet that these findings are applicable to humans infected with malaria. In fact, in the case of $P$. vivax, some liver stages can survive for years in the hepatocytes in a dormant state without being destroyed by CTL.

Cytotoxic T-cell (CTL) epitopes in the C-terminal region of the CS protein of $P$. berghei and $P$. yoelii (Romero et al., 1989; Weiss et al., 1990) have recently been identified. Several T-cell clones which recognize the $P$. bergheiepitope when passively transferred to mice protect them against challenge with $P$. berghei sporozoites. These findings raise puzzling questions about the mechanisms involved in the afferent and effector stages of the immune response to spozoroites. According to currently accepted concepts, CD8 ${ }^{+} \mathrm{CTL}$ and $\mathrm{CD}^{+}$helper cells must recognize peptides from processed sporozoite antigens in association with class I and class II MHC, respectively. Sporozoites invade hepatocytes, where they continue their development, or are ingested by macrophages where they are destroyed. If the anatomy of the liver is taken into consideration - an endothelium separates the hepatocytes from the circulating blood cells - sensitization most likely takes places in macrophages, and not in hepatocytes, which are devoid of class II antigens and cannot therefore sensitize T-helper cells, necessary for antibody production, and probably also to generate $\mathrm{CD}^{+}$CTLs. Moreover, human hepatocytes have small amounts of class I antigen; recent studies failed to detect any products of the A or B loci in liver cells (Stam et al., 1990).

What about the possibility of antigenic variation under pressure of the immune system? In our opinion, similarly to what occurs in viral diseases, the immunologic pressure which we should fear will be antibody-mediated and directed mainly against the repeats. Two types of $P$. vivax repeats have been reported (Rosenberg et al., 1989), and extensive variation of repeats has been documented in the monkey malarias (Galinski et al., 1987). No variation, however, has been reported in the repeats of $P$. falciparum.

As for the observed variation in the C-terminal $T h 2 R$ region, it may not originate from selective pressure by CTL as proposed by McCutchan et al. (1989). Epidemiological evidence does not support the idea that there is selective pressure of the immune system on the sporozoite stage of the malaria parasite, or that the $\mathrm{Th} 2 \mathrm{R}$ region is the major target of this selective pressure. Probably because the dose of sporozoites injected by mosquitoes is extremely small, and many parasites take refuge in hepatocytes, a cell which as mentioned lacks MHC class II and has little MHC class $\mathrm{I}$, the antibody responses against CS take a very long time to develop. It seems unlikely under these circumstances that a very effective CTL response would develop early.

The McCutchan hypothesis requires that immunization with one $\mathrm{Th} 2 \mathrm{R}$ variant does not protect against challenge with another variant, and that the polymorphic human population in endemic areas recognize only or mainly the polymorphic Th2R epitope of the CS protein. Otherwise $\mathrm{CD}^{+} \mathrm{CTL}$ against other epitopes would still kill the hepatocytes containing the Th2R variants. As mentioned, the human volunteers vaccinated with irradiated sporozoites were protected when challenged with different isolates of sporozoites. Another assumption is that CTL kill infected hepatocytes directly and that lymphokines such as $\gamma$-interferon, lymphotoxin and TNF have no role in destroying 
the liver stages. $\mathrm{CD} 8^{+} \mathrm{CTL}$ are good producers of $\gamma$-interferon, and non-specific effects on liver stages seem unavoidable.

There are alternative explanations for the nature of the selective pressure on the Th2R region. Sporozoites live in two hosts, and CS is expressed - though in smaller amounts - in sporozoites from oocysts of the mosquito stomach. After the oocysts rupture, the sporozoites migrate in the hemocoele and enter the salivary glands by traversing an epithelial cell lining. Anopheles mosquitoes can vary enormously in their vector competency, even within the same species or subspecies. The nature of the polymorphic genes underlying this variation in susceptibility of mosquitoes to malaria infection is unknown. Perhaps the CS, and in particular the $\mathrm{Th} 2 \mathrm{R}$ region, plays a role during the development of sporozoites in the mosquito, and the selective pressure for variation arises from polymorphic mosquito traits. Even if the selective pressure for variation is in the vertebrate host, the immune system may not be involved. For example, the Th2R region may interact with a polymorphic molecule in the vertebrate host (receptor?).

In short, for maximum efficacy, a sporozoite malaria vaccine should incorporate epitopes from the CS protein capable of inducing high titers of neutralizing antibodies. If the findings in rodents are applicable to humans, the vaccine should also sensitize CTL and other T-cells that respond with the production of $\gamma$-interferon to sporozoite antigens introduced during challenge. Another important consideration is that a malaria vaccine for use in endemic areas should include not only the CS antigen, but also blood-stage antigens. On the basis of our current knowledge, this ideal malaria vaccine is not likely to become available for widespread use in the near future. Therefore prevention of morbidity and mortality from this disease in endemic areas should continue to rely on integrated primary measures of health care, on chemotherapy, chemoprophylaxis and mosquito control.

\section{REFERENCES}

Ballou W. R., Hoffman S. L., Sherwods J. A., Hollingdale M. R., Neva F. A., Hockmeyer W. T., Gordon D. M., Schneider I., Wirtz R. A., Young J. E., Wasserman G. F., Reeve P., Diggs C. L., Chulay J. D. : Safety and efficacy of a recombinant DNA Plasmodium falciparum sporozoite vaccine. Lancet, 1987 , $i$, 1277-1281.

Clyde D. F., McCarthy V. Q., Miller R. M., Hornick R. B. : Specificity of protection of man immunized against sporozoiteinduced falciparum malaria. Am. J. Med. Sci., 1973, 266, 398-403.

Davis J. R., Murphy J. R., Clyde D. F., Baqar S., Cochrane A., Zavala F., Nussenzweig R. S. : Estimate of Plasmodium falciparum sporozoite content of Anopheles stephensi used to challenge human volunteers. Am. J. Trop. Med. Hyg., 1989, 40, 128-130.

DeGroot A. S., Johnson A. H., Maloy W. L., Quakyi I. A., Riley E. M., Menon A., Banks S. M., Berzofsky J. A.,
Good M. F. : Human T-cell recognition of polymorphic epitopes from malaria circumsporozoite protein. J. Immunol., 1989, 142, 4000-4005.

Ferreira A., Schofield L., Enea V., Schellekens H., Van der Meide P., Collins W. E., Nussenzweig R. S., Nussenzweig V. : Inhibition of development of exoerythrocytic forms of malaria parasites by $\gamma$-interferon. Science, 1986, 232, 881-884.

Galinski M. R., Arnot D. E., Cochrane A. H., Barnwell J. W., Nussenzweig R. S., Enea V. : The circumsporozoite gene of the Plasmodium cynomolgi complex. Cell, 1987, 48, 311-319.

Herrington D. A., Clyde D. F., Losonsky G., Cortesia M., Murphy J. R., Davis J., Baqar S., Felix A. M., Heimer E. P., Gillessen D., Nardin E., Nussenzweig R. S., Nussenzweig V., Hollingdale M. R., Levine M. M. : Safety and immunogenicity in man of a synthetic peptide malaria vaccine against Plasmodium falciparum sporozoites. Nature, 1987, 328, 257-259.

McCutchan T. F., Good M. F., Miller L. H. : Polymorphism in the circumsporozoite (CS) protein of Plasmodium falciparum. Immunol. Today, 1989, 5, 143-146.

Nardin E. H., Herrington D. A., Davis J., Levine M., Stuber D., Takacs B., Caspers P., Barr P., Altszuler R., Clavijo P., Nussenzweig R. S. : Conserved repetitive epitope recognized by $\mathrm{CD}^{+}{ }^{+}$clones from a malaria immunized volunteer. Science, 1989, 246, 1603-1606.

Nussenzweig V., Nussenzweig R. S. : Rationale for the development of an engineered sporozoite malaria vaccine. Adv. Immunol., 1989, 45, 283-334.

Romero P., Maryanski J. L., Corradin G., Nussenzweig R. S., Nussenzweig V., Zavala F. : Cloned cytotoxic T-cells recognize an epitope in the circumsporozoite (CS) protein and protect against malaria. Nature, 1989, 341, 323-326.

Rosenberg R., Wirtz R. A., Lanar D. E., Sattabongkot J., Hall T., Waters A. P., Prasittisuk C. : Circumsporozoite protein heterogeneity in the human malaria parasite Plasmodium vivax. Science, 1989, 245, 973-976.

Schofield L., Villaquiran J., Ferreira A., Schellekens H., Nussenzweig R. S., Nussenzweig, V. $\gamma$-Interferon, CD8 ${ }^{+}$T-cells and antibodies required for immunity to malaria sporozoites. Nature, 1987, 330, 664-666.

Sinigaglia F., Guttinger M., Kilgus J., Doran D. M., Matile H., Etlinger H., Trzeciak A., Gillessen D., Pink J. R. L. : A malaria $\mathrm{T}$ cell epitope recognized in association with most mouse and human MHC class II molecules. Nature, 1988, 336, 778-780.

Stam N. J., Vroom T. M., Peters P. J., Pastoors E. B., Ploegh H. L. : HLA-A and HLA-B-specific monoclonal antibodies reactive with free heavy chains in Western blots, in formalin-fixed, paraffin-embedded tissue sections and in cryo-immuno-electron microscopy. Int. Immunol., 1990, 2, 113-125.

Tam J. P., Clavijo P., Lu Y.-A., Nussenzweig V., Nussenzweig R. S., Zavala F. : Incorporation of $T$ and $B$ epitopes of the circumsporozoite protein in a chemically defined synthetic vaccine against malaria. J. Exp. Med., 1990, 171, 299-306.

Weiss W. R., Sedegah M., Beaudoin R. L., Miller L. H., Good M. F. : $\mathrm{CD}^{+} \mathrm{T}$ cells (cytotoxic/suppressors) are required for protection in mice immunized with malaria sporozoites. Proc. Natl. Acad. Sci. USA, 1988, 85, 573-576.

Weiss W. R., Mellouk S., Houghten R. A., Sedegah M., Kumar S., Good M. F., Berzofsky J. A., Miller L. H., Hoffman S. L. : Cytotoxic $\mathrm{T}$ cells recognize a peptide from the circumsporozoite protein on malaria-infected hepatocytes. J. Exp. Med., $1990,171,763-773$.

Zavala F., Tam J. P., Barr P. J., Romero P. J., Ley V., Nussenzweig R. S., Nussenzweig V. : Synthetic peptide vaccine confers protection against murine malaria. J. Exp. Med., 1987, 166, 1591-1596. 